\title{
Influence of population and exercise protocol characteristics on hemodynamic determinants of post-aerobic exercise hypotension
}

\author{
L.C. Brito, A.C.C. Queiroz and C.L.M. Forjaz \\ Laboratório de Hemodinâmica da Atividade Motora, Departamento de Biodinâmica do Movimento do Corpo Humano, \\ Escola de Educação Física e Esporte, Universidade de São Paulo, São Paulo, SP, Brasil
}

\begin{abstract}
Due to differences in study populations and protocols, the hemodynamic determinants of post-aerobic exercise hypotension (PAEH) are controversial. This review analyzed the factors that might influence PAEH hemodynamic determinants, through a search on PubMed using the following key words: "postexercise" or "post-exercise" combined with "hypotension", "blood pressure", "cardiac output", and "peripheral vascular resistance", and "aerobic exercise" combined only with "blood pressure". Forty-seven studies were selected, and the following characteristics were analyzed: age, gender, training status, body mass index status, blood pressure status, exercise intensity, duration and mode (continuous or interval), time of day, and recovery position. Data analysis showed that 1) most postexercise hypotension cases are due to a reduction in systemic vascular resistance; 2) age, body mass index, and blood pressure status influence postexercise hemodynamics, favoring cardiac output decrease in elderly, overweight, and hypertensive subjects; 3) gender and training status do not have an isolated influence; 4) exercise duration, intensity, and mode also do not affect postexercise hemodynamics; 5) time of day might have an influence, but more data are needed; and 6) recovery in the supine position facilitates systemic vascular resistance decrease. In conclusion, many factors may influence postexercise hypotension hemodynamics, and future studies should directly address these specific influences because different combinations may explain the observed variability in postexercise hemodynamic studies.
\end{abstract}

Key words: Blood pressure; Exercise; Cardiac output; Peripheral vascular resistance

\section{Introduction}

Physical exercise, especially aerobic exercise, is recommended for reducing blood pressure (BP). A recent review (1) reported that a period of aerobic training (chronic effect) reduces systolic/diastolic BP in normotensive and hypertensive individuals, with greater reductions observed in hypertensive individuals $(-1 /-2$ and $-8 /$ $-5 \mathrm{mmHg}$, respectively). In addition, a significant reduction in BP has also been reported after a single session of aerobic exercise (acute affect) in normotensive and hypertensive individuals $(-2 /-3$ and $-9 /-9 \mathrm{mmHg}$, respectively) (2), and this acute hypotensive effect has been called post-aerobic exercise hypotension (PAEH) (3).

$\mathrm{PAEH}$ is defined as a reduction in BP after a session of aerobic exercise in comparison with $\mathrm{BP}$ measured before exercise and/or measured on a control day without exercise (3). PAEH has been demonstrated as clinically relevant because it is significant in magnitude and is sustained for a prolonged period after exercise (3). Moreover, it has been reported in different populations, including individuals who are hypertensive (4-9), prehypertensive $(10,11)$, and normotensive $(5,12-30)$.

Many studies have investigated the hemodynamic determinants of PAEH. Some of them attribute PAEH to reduced cardiac output (CO) $(6,9,12,15,19,21-24,30-34)$, while others report a peripheral vascular resistance (PVR) reduction $(4,7,16-18,20-23,25-29,33-53)$. This controversy suggests that some other factors could influence these determinants.

The characteristics of the study population and protocols influence the magnitude and duration of $\mathrm{PAEH}$ $(5,15,25)$. Therefore, these characteristics may also influence the hemodynamic determinants of PAEH, but

Correspondence: C.L.M. Forjaz, Av. Prof. Mello Moraes, 65, 05508-030 São Paulo, SP, Brasil. Fax: +55-11-3813-5921. E-mail: cforjaz@usp.br 
this question has not been systematically studied. A better understanding of these influences may provide a basis for a more effective exercise prescription aimed at BP reduction after exercise and may also facilitate comparisons among studies in the literature, thereby improving scientific knowledge in this field.

The purpose of this study was to analyze the existing data about the hemodynamic determinants of PAEH by investigating the possible influence of the characteristics of the population and the study protocol on these determinants.

\section{Material and Methods}

A literature search was performed for studies that measured $\mathrm{CO}$ and PVR after a session of aerobic exercise that produced PAEH. The search was conducted on PubMed with the following terms combined: "postexercise" or "post-exercise" combined with "hypotension", "blood pressure", "cardiac output", and "peripheral vascular resistance", and "aerobic exercise" combined only with "blood pressure". Studies published in English until February 2013 were included.

The characteristics of the population and protocols were extracted from the studies included in this review. With regard to the population, the following characteristics were analyzed: age (young: 18-39 years, middle-aged: 40-60 years, and elderly: $>60$ years old) (54); sex (male and female); training status (sedentary and trained in accordance with the authors' report); body mass index (normal BMI $\leq 25 \mathrm{~kg} / \mathrm{m}^{2}$ and excess body weight BMl $\geq 25 \mathrm{~kg} / \mathrm{m}^{2}$ ), and $\mathrm{BP}$ status (systolic/diastolic BP: normotensive $<120$ / $80 \mathrm{mmHg}$, prehypertensive 120 to 139 and/or 80 to $89 \mathrm{mmHg}$, and hypertensive $\geq 140 / 90 \mathrm{mmHg}$ ) (55). Regarding the experimental protocol, the following characteristics were analyzed: exercise duration (short: $<30 \mathrm{~min}$, medium: $\geq 30 \mathrm{~min}$ and $<60 \mathrm{~min}$, and long: $\geq 60 \mathrm{~min}$ ), intensity (light: $<50 \%$, moderate: $\geq 50 \%$ and $<80 \%$, high: $\geq 80 \% \mathrm{VO}_{2}$ peak), mode (continuous and interval), time of day when the exercise was performed (morning and/or afternoon), and body position adopted during measurements (sitting or supine). Two independent investigators performed the search and obtained the information from the studies. Disagreements were solved by consensus.

A descriptive analysis of the hemodynamic determinants (CO and PVR) of PAEH cited in the studies was conducted according to the different influences. In addition, a frequency comparison of the occurrence of $\mathrm{CO}$ and PVR reduction after exercise within the studies was performed for each influence using a chi-square test, in which $\mathrm{P} \leq 0.05$.

\section{Results}

A total of 1216 studies were selected from the literature search. Of these, 439 did not investigate aerobic exercise, 274 did not investigate the acute effects of exercise, 421 did not measure hemodynamic determinants, and 39 did not observe PAEH. Thus, 43 studies reported the hemodynamic determinants of $\mathrm{PAEH}$ after aerobic exercise and were subsequently included in this review. Moreover, four studies were cited in references.

The main characteristics of the 47 studies are shown in Table 1 (studies with young subjects) and Table 2 (studies with middle-aged and elderly subjects). Table 3 shows the frequency of reduction of each hemodynamic determinant ( $\mathrm{CO}$ and $\mathrm{PVR}$ ) with regard to each studied factor of influence.

The 47 studies included in the analysis comprise 93 different experimental cases. PVR decreased after exercise in $64(69 \%)$ cases, while CO decreased in 14 $(15 \%)$ cases. In the other cases, none of the hemodynamic determinants decreased significantly.

\section{Population characteristics}

In terms of age, PVR decreased in $74 \%$ of cases involving young subjects; in middle-aged subjects, PVR decreased in $62 \%$ of cases; and PVR did not decrease in the elderly. However, $\mathrm{CO}$ reduced in $75 \%$ of cases for this group. The frequency of $\mathrm{CO}$ and PVR reduction was influenced by age $(P=0.00)$.

When considering sex, a reduction in PVR occurred in $89 \%$ of female cases and $60 \%$ of male cases, without any significant difference between genders.

When analyzing training status, PVR decreased in $62 \%$ and $69 \%$ of cases involving sedentary and trained subjects, respectively. These frequencies were not significantly different.

For subjects with normal BMI, PVR decreased in $75 \%$ of cases, while CO decreased in 13\%. For subjects with excess body weight, PVR decreased in $44 \%$ of cases, whereas CO decreased in $28 \%$. The frequencies of CO and PVR reduction were significantly different in terms of $B M I$ status $(P=0.05)$.

Regarding BP status, PVR and CO decreased in $72 \%$ and $13 \%$ of normotensive subjects, respectively. For those who were prehypertensive, PVR decreased in 33\% of cases, but CO did not change at any time. On the other hand, for those who were hypertensive, PVR decreased in $58 \%$ of cases, while CO was reduced in $42 \%$. As such, there was a significant difference in the frequencies related to BP status $(P=0.00)$.

\section{Exercise protocol characteristics}

There was no significant difference between the frequencies of PVR and CO reductions after exercise in relation to exercise duration, intensity, or mode. PVR reduction was observed in $73 \%, 59 \%$, and $80 \%$ of cases with short, medium, and long exercise durations, respectively. After light-, moderate-, and high-intensity exercises, decreased PVR was observed in 100\%, 65\%, and $77 \%$ of cases, respectively. Finally, a PVR decrease was reported in $70 \%$ of cases with continuous exercise and in 


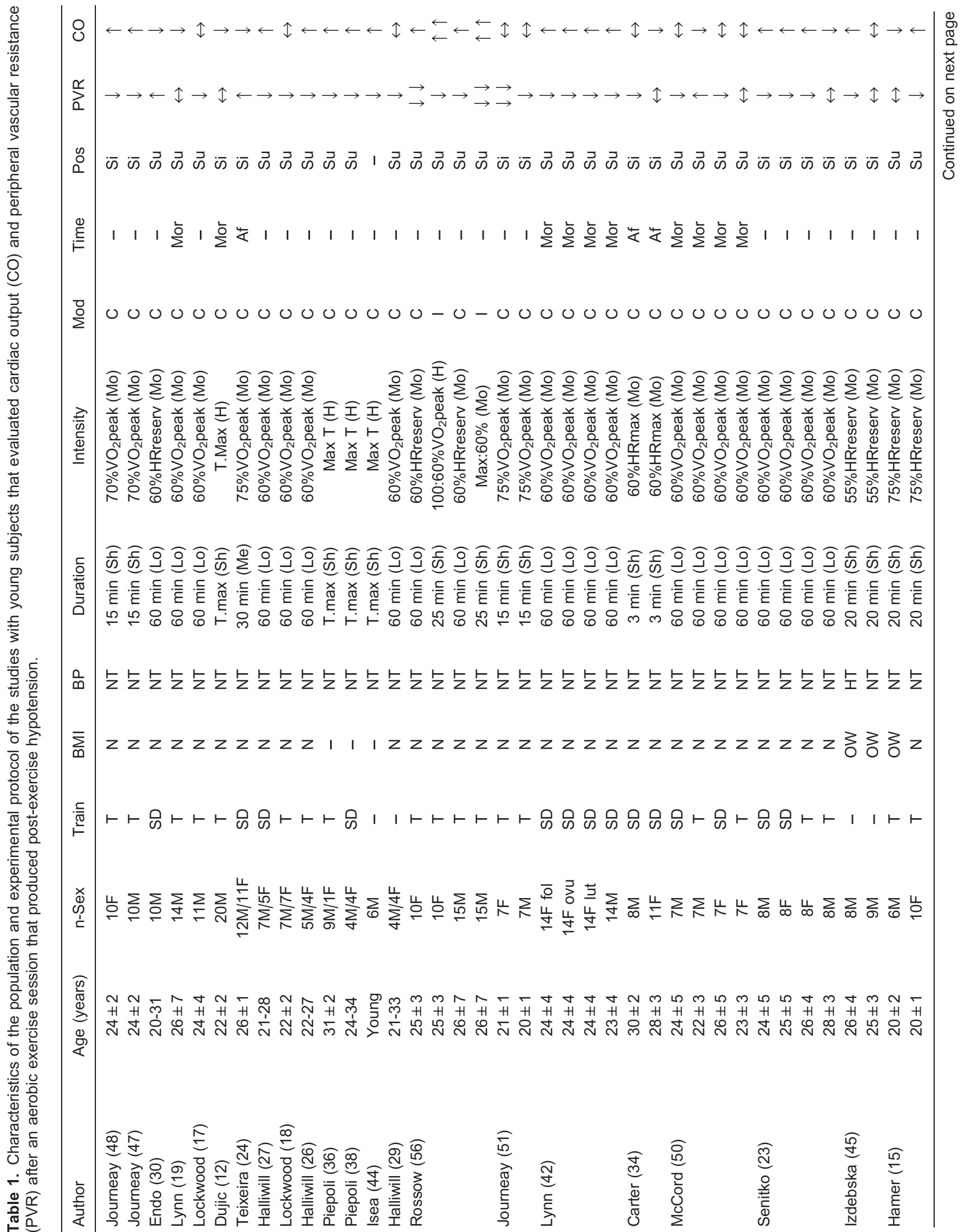




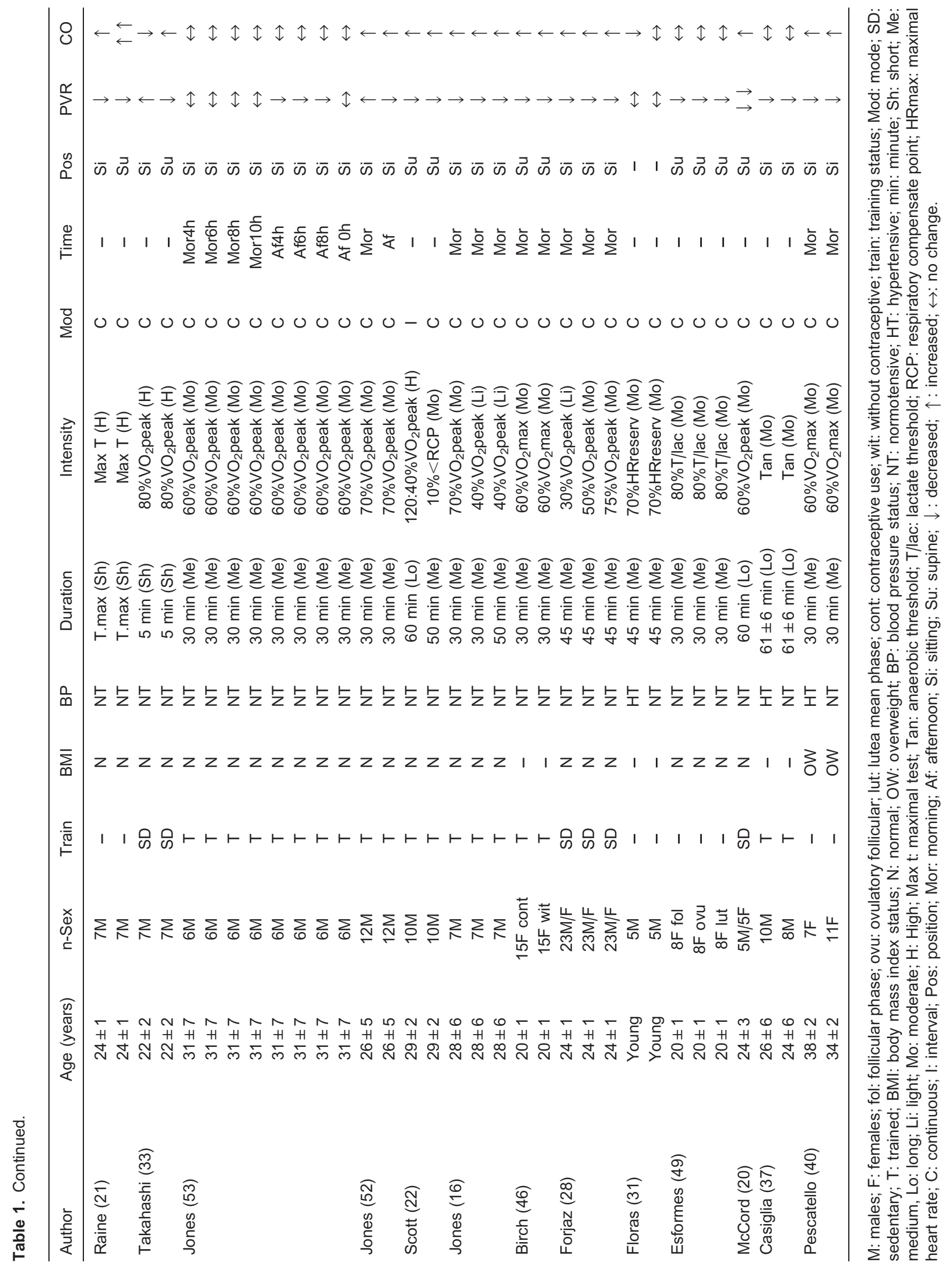




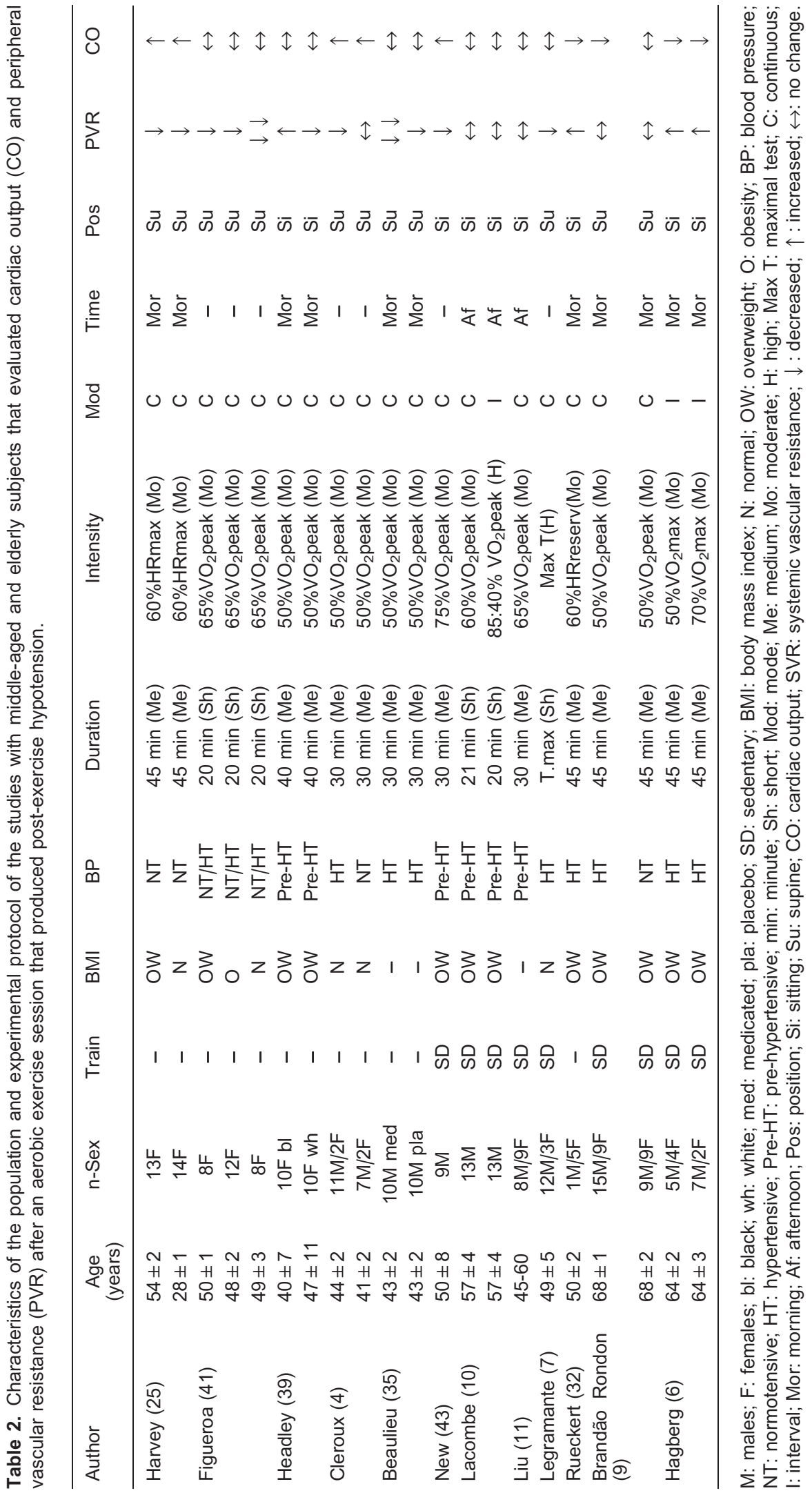


Table 3. Frequency of occurrence of cardiac output (CO) and peripheral vascular resistance (PVR) reduction after aerobic exercise in the different experimental conditions reported in the studies included in this review concerning the possible factors of influence.

\begin{tabular}{|c|c|c|c|c|c|c|c|c|}
\hline & Conditions & $\downarrow P V R$ & $\downarrow \mathrm{CO}$ & $\leftrightarrow$ & $\begin{array}{c}\downarrow \text { PVR } \\
(\%)\end{array}$ & $\begin{array}{c}\downarrow \mathrm{CO} \\
(\%)\end{array}$ & Chi-square & $P$ \\
\hline \multicolumn{9}{|l|}{ Age } \\
\hline Young & 73 & 54 & 10 & 9 & 74.0 & 13.4 & 16.71 & $0.00^{*}$ \\
\hline Middle-aged & 16 & 10 & 1 & 5 & 62.5 & 6.3 & & \\
\hline Elderly & 4 & 0 & 3 & 1 & 0 & 75.0 & & \\
\hline \multicolumn{9}{|l|}{ Sex } \\
\hline Female & 27 & 24 & 1 & 2 & 88.9 & 3.7 & 8.19 & 0.09 \\
\hline Male & 45 & 27 & 8 & 10 & 60.0 & 17.8 & & \\
\hline \multicolumn{9}{|l|}{ Training status } \\
\hline Sedentary & 29 & 18 & 7 & 4 & 62.1 & 24.1 & 1.51 & 0.47 \\
\hline Trained & 39 & 27 & 5 & 7 & 69.2 & 12.8 & & \\
\hline \multicolumn{9}{|c|}{ Body mass index status } \\
\hline Normal & 63 & 47 & 8 & 8 & 74.6 & 12.7 & 5.84 & $0.05^{*}$ \\
\hline Overweight & 18 & 8 & 5 & 5 & 44.4 & 27.8 & & \\
\hline \multicolumn{9}{|c|}{ Blood pressure status } \\
\hline NT & 72 & 52 & 9 & 11 & 72.2 & 12.5 & 19.13 & $0.00^{*}$ \\
\hline Pre-HT & 6 & 2 & 0 & 4 & 33.3 & 0.0 & & \\
\hline $\mathrm{HT}$ & 12 & 7 & 5 & 0 & 58.3 & 41.7 & & \\
\hline \multicolumn{9}{|c|}{ Exercise duration } \\
\hline Short & 26 & 19 & 4 & 3 & 73.1 & 15.4 & 6.34 & 0.18 \\
\hline Medium & 42 & 25 & 6 & 11 & 59.5 & 14.3 & & \\
\hline Long & 25 & 20 & 4 & 1 & 80.0 & 16.0 & & \\
\hline \multicolumn{9}{|c|}{ Exercise intensity } \\
\hline Light & 6 & 6 & 0 & 0 & 100.0 & 0.0 & 4.01 & 0.41 \\
\hline Moderate & 74 & 48 & 12 & 14 & 64.9 & 16.2 & & \\
\hline High & 13 & 10 & 2 & 1 & 76.9 & 15.4 & & \\
\hline \multicolumn{9}{|l|}{ Exercise mode } \\
\hline Continuous & 87 & 61 & 12 & 14 & 70.1 & 13.8 & 1.76 & 0.42 \\
\hline Interval & 6 & 3 & 2 & 1 & 50.0 & 33.3 & & \\
\hline \multicolumn{9}{|l|}{ Time of day } \\
\hline Morning & 36 & 21 & 7 & 8 & 58.3 & 19.4 & 0.92 & 0.63 \\
\hline Afternoon & 11 & 5 & 2 & 4 & 45.5 & 18.2 & & \\
\hline \multicolumn{9}{|l|}{ Position } \\
\hline Sitting & 45 & 26 & 8 & 11 & 57.8 & 18.2 & 7.18 & $0.03^{*}$ \\
\hline Supine & 45 & 37 & 5 & 3 & 82.2 & 11.1 & & \\
\hline
\end{tabular}

NT: normotensive; Pre-HT: pre-hypertensive; HT: hypertensive; $\downarrow$ : decreased; $\leftrightarrow$ : no change. * $\mathrm{P} \leq 0.05$ (chi-square test).

$50 \%$ of cases with interval exercise.

When exercise was performed in the morning and the afternoon, a PVR decrease was reported in $58 \%$ and $45 \%$ of cases, respectively, which are similar.

In regard to body position adopted at the time period of the measurement, PVR reduction was observed in $82 \%$ and $58 \%$ of cases of supine and sitting recovery, respectively, while CO decrease was reported in $18 \%$ and $11 \%$ of cases. These frequencies of occurrence were significantly different $(P=0.03)$.

\section{Discussion}

This review confirms the disseminated conception that, in most cases, PAEH is related to a reduction in PVR. However, this review also revealed that $\mathrm{CO}$ reduction was responsible for $\mathrm{PAEH}$ under many circumstances. Some factors related to the characteristics of the study protocols and population may influence the hemodynamic determinants of PAEH. In this sense, the current results suggest that a $\mathrm{CO}$ reduction after exercise is facilitated when elderly, hypertensive, and overweight subjects were studied and when recovery was performed in the sitting position.

\section{Population characteristics}

PAEH occurs at all ages, as confirmed by studies of individuals who are young $(11,12,15-24,26-31,33-37$, 
40-42,45-53,56), middle-aged $(4,7,10,25,32,39)$, and elderly $(6,9)$. Aging leads to structural alterations in the cardiovascular system (57) that can influence PAEH hemodynamic determinants. The present findings suggest that postexercise PVR reduction occurs in young and middle-aged people $(4,7,17,18,20,22,25-29,39-41,45,46$, $48,49,51)$, while a reduction in $\mathrm{CO}$ is more evident in those who are elderly $(6,9)$. We were only able to find one study that directly compared postexercise hemodynamics in different age groups (25). This study reported a reduction in PVR after exercise in young and middleaged females (as observed in this review), but it did not assess elderly subjects (25). It is possible that an increase in arterial stiffness and PVR, as well as a decrease in endothelial function associated with aging (57), hinders postexercise PVR reduction after exercise, facilitating stroke volume and $\mathrm{CO}$ reduction in the elderly. Nevertheless, it is interesting to note that some studies reported postexercise $\mathrm{CO}$ reductions in young and middle-aged individuals $(12,19,24,30-32)$, which suggests that other factors besides age also influence PAEH hemodynamic determinants.

At rest, females have lower PVR than males (58). Besides this difference, the results of this review did not suggest an influence of sex on post-aerobic exercise hemodynamics, although a $P$ value of 0.09 was observed for the chi-square test. We identified five studies that directly compared sex effects on PAEH hemodynamic determinants. From those studies, two did not identify any difference between sexes $(42,56)$, and two observed a $\mathrm{CO}$ reduction in males and a PVR reduction in females; however, these differences were only observed in trained subjects $(23,50)$. The fifth study reported another pattern: a reduction in $\mathrm{CO}$ and PVR in females and males, respectively (34). Thus, the possible gender influence on $\mathrm{CO}$ and PVR behavior after exercise deserves further investigation.

Among other adaptations, aerobic training improves endothelial function, decreases PVR, and increases plasma volume (59). All of these changes may influence PAEH hemodynamic determinants. However, this review did not identify any influence related to training status per se. In fact, studies that directly compared postexercise $\mathrm{CO}$ and PVR responses in trained and sedentary individuals suggest that the influence of training status on PAEH hemodynamics may be gender dependent. These studies observed that training status did not affect female PAEH determinants, but $\mathrm{CO}$ decreased in trained males and PVR decreased in sedentary males after aerobic exercise $(23,50)$. As in this review, training status and sex were independently considered, and their combined influence was not assessed.

Excess body weight is associated with cardiovascular alterations $(60,61)$, which might affect PAEH hemodynamic determinants. In this review, although PVR reduction was the predominant determinant of $\mathrm{PAEH}$ in both normal subjects and individuals with excess weight, in the second group of subjects, CO reduction after exercise was observed in many cases $(28 \%)$. Studies that directly compared postexercise hemodynamics in individuals with excess body weight and their normal weight peers reported controversial results. One study reported a $\mathrm{CO}$ reduction in overweight subjects and a PVR reduction in normal-weight subjects (15). Other studies reported PVR reductions in both groups $(25,41)$. It is important to highlight that when overweight subjects were compared with obese subjects, PVR decreased for both (41). Thus, the effect of BMI status on PAEH determinants is not yet clear, but the presence of excess body weight might facilitate $\mathrm{CO}$ reduction.

Hypertension also promotes cardiovascular alterations, such as arterial stiffness, PVR increase, and endothelial dysfunction (57), which may pose a difficulty to postexercise vasodilation and PVR decrease. In accordance with the present review, when hypertensive subjects were studied, CO decreased after exercise in $42 \%$ of cases. To our knowledge, six studies directly compared responses after exercise in hypertensive and normotensive subjects, yet each revealed different results $(4,9,31,37,40,45)$. In two studies, PVR decreased equally in both groups $(37,40)$. In two others, only hypertensive individuals presented PVR reduction $(4,45)$, and only hypertensive individuals showed $\mathrm{CO}$ reductions in two other studies $(9,31)$. Thus, although there was no unanimity in these studies, they suggest that the presence of hypertension may facilitate postexercise $\mathrm{CO}$ reduction, which should be further addressed.

\section{Exercise protocol characteristics}

Regarding exercise characteristics, it is known that exercise duration, intensity, and mode affect $\mathrm{PAEH}$ magnitude and duration (14,28,62-64). However, the results of this review suggest that none of these factors affect PAEH hemodynamic determinants. These results are in agreement with previous studies that directly compared different exercise protocols. Two studies found similar postexercise hemodynamics regardless of exercise duration $(16,56)$. Furthermore, six studies directly compared different exercise intensities $(6,10,16,22,28,56)$; however, only the last study (56) reported a difference in postexercise hemodynamics, with PVR reduction occurring only after intense and not after moderate exercise in males, but not in females (56). Three studies directly compared continuous and interval exercise $(10,22,56)$, but only the last study (56) reported a difference, with interval exercise producing a higher PVR reduction. Thus, exercise characteristics (duration, intensity, and mode) do not seem to influence PAEH hemodynamic determinants.

Circadian physiological alterations affect hemodynamic determinants $(65,66)$. Previous studies that compared postexercise hemodynamics in the morning and afternoon suggest a decrease in PVR only after afternoon 


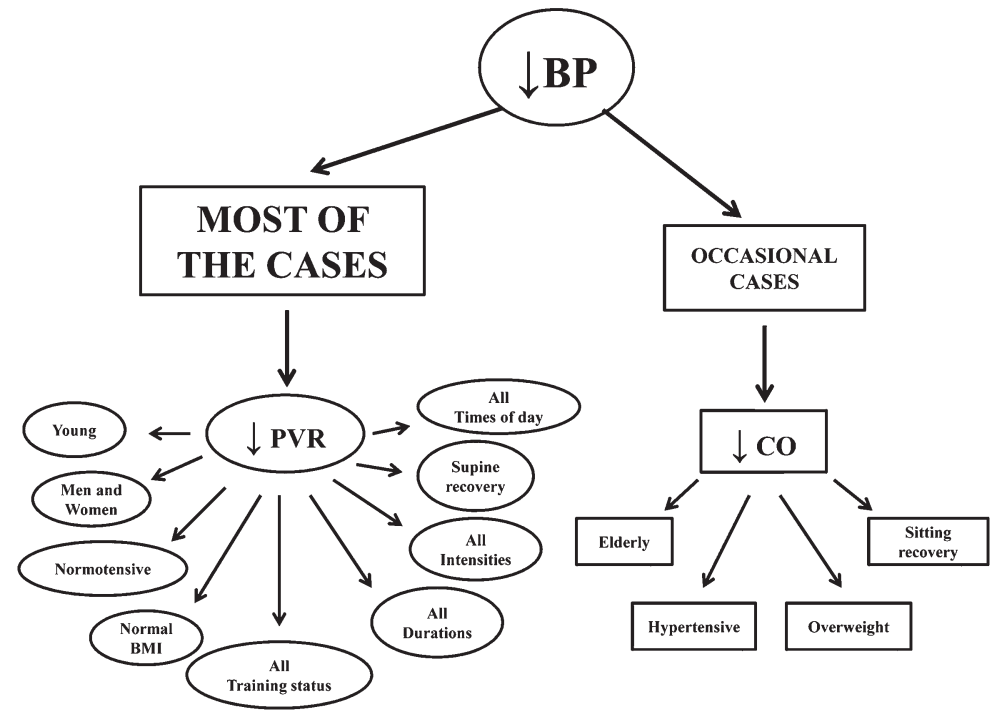

Figure 1. Schematic depicting the main findings of this review regarding the population and exercise protocol characteristics that may influence hemodynamic determinants (CO: cardiac output; PVR: peripheral vascular resistance) of post-aerobic exercise hypotension. exercise $(13,52,53)$. However, the results of this review did not identify any differences in PAEH hemodynamic determinants when exercise is performed in the morning and in the afternoon. As such, more data are needed.

Many PAEH studies have been performed with measurements taken in the supine position. This position facilitates hemodynamic assessment and avoids orthostatic stress, leading to a more specific analysis of exercise effects. However, the practical applicability is low for these measures because subjects do not tend to lie down after exercise. Thus, other studies performed hemodynamic evaluations in the sitting position. Orthostatic stress induced by the sitting position affects hemodynamic responses at rest (67) and may change hemodynamic behavior after exercise. Indeed, the present review suggests that the supine position facilitates PVR reduction, while the sitting position favors $\mathrm{CO}$ reduction after exercise. The same results were found in two studies that directly compared PAEH in these positions $(21,33)$.

\section{Possible influencing mechanisms}

The mechanisms by which old age, hypertension status, increased $\mathrm{BMI}$, and sitting position facilitate $\mathrm{CO}$ decrease and hamper PVR decrease after a single session of aerobic exercise are out of the scope of the present review. In addition, few studies investigated these possible mechanisms, and their results are controversial. Nevertheless, a hypothesis can be formulated and should be tested in the future. After a session of aerobic exercise, multiple hemodynamic responses were observed. Venous return decreases (9), leading to a decrease in stroke volume that favors $\mathrm{CO}$ reduction. Furthermore, it is known that venous return decrease deactivates the cardiopulmonary reflex, leading to an increase in peripheral sympathetic activity that increases PVR (68). In addition, a sympatholytic effect and a decrease in the alphaadrenergic response to sympathetic stimuli have been reported after an aerobic exercise session (26), which may lead to a reduction in PVR. Moreover, it is supposed that some vasodilatory substances secreted by exercise, like nitric oxide, histamine, and prostaglandins, may contribute to maintaining vasodilation after exercise (69). However, the roles of some of these substances, such as nitric oxide (29) and prostaglandins (17), have been refuted in some studies. Finally, as BP decreases after exercise, the baroreflex is deactivated and, consequently, heart rate $(\mathrm{HR})$ increases and peripheral sympathetic activity is stimulated (68). However, after a session of aerobic exercise, baroreflex sensitivity to $\mathrm{HR}$ control is blunted (70), and the set point of this reflex for peripheral adjustments is changed (26). Thus, these complex mechanisms interact after exercise, leading to decreased PVR in most circumstances and to decreased $\mathrm{CO}$ in some circumstances. It is possible that, as in elderly, hypertensive, and overweight subjects, sympathetic activity $(57,71)$ and cardiopulmonary reflexes (68) are exacerbated while endothelial function $(57,60)$ and baroreflex control (72) are impaired, PVR decrease after exercise is mitigated, and $\mathrm{CO}$ decrease is facilitated, which may explain the differences in PAEH suggested by this review. Once again, this is just a hypothesis that should be investigated in the future.

This review has some limitations. The search for articles was only carried out on PubMed. Although PubMed is the main health research database and includes better quality studies than other databases, the inclusion of other databases may have increased the number of studies. On the other hand, a strong aspect of this review is its novelty in presenting a quantitative 
analysis of the frequencies of $\mathrm{CO}$ and PVR reduction after exercise with regard to each possible influence factor. We think this approach minimized the subjectivity of an analytic systematic review. Nevertheless, as a review, the results are only indicative of possible influence, and specific studies addressing the real effect of each influence should be conducted in the future.

In conclusion, the present literature review revealed that, in most cases, PAEH occurs following a decrease in PVR (Figure 1). However, $\mathrm{CO}$ reduction may be an important determinant of $\mathrm{PAEH}$ in some circumstances. The factors that might favor post-aerobic exercise $\mathrm{CO}$ reduction are advanced age, presence of excess body

\section{References}

1. Cornelissen VA, Smart NA. Exercise training for blood pressure: a systematic review and meta-analysis. J Am Heart Assoc 2013; 2: e004473, doi: 10.1161/JAHA.112. 004473.

2. Cardoso CG Jr, Gomides RS, Queiroz AC, Pinto LG, da Silveira Lobo $F$, Tinucci $T$, et al. Acute and chronic effects of aerobic and resistance exercise on ambulatory blood pressure. Clinics 2010; 65: 317-325, doi: 10.1590/ S1807-59322010000300013.

3. Kenney MJ, Seals DR. Postexercise hypotension. Key features, mechanisms, and clinical significance. Hypertension 1993; 22: 653-664, doi: 10.1161/01.HYP.22.5.653.

4. Cleroux J, Kouame N, Nadeau A, Coulombe D, Lacourciere $Y$. Aftereffects of exercise on regional and systemic hemodynamics in hypertension. Hypertension 1992; 19: 183-191, doi: 10.1161/01.HYP.19.2.183.

5. Forjaz CL, Tinucci T, Ortega KC, Santaella DF, Mion D Jr, Negrao CE. Factors affecting post-exercise hypotension in normotensive and hypertensive humans. Blood Press Monit 2000; 5: 255-262, doi: 10.1097/00126097-20001000000002.

6. Hagberg JM, Montain SJ, Martin WH III. Blood pressure and hemodynamic responses after exercise in older hypertensives. J Appl Physiol 1987; 63: 270-276.

7. Legramante JM, Galante A, Massaro M, Attanasio A, Raimondi G, Pigozzi F, et al. Hemodynamic and autonomic correlates of postexercise hypotension in patients with mild hypertension. Am J Physiol Regul Integr Comp Physiol 2002; 282: R1037-R1043.

8. MacDonald JR, Rosenfeld JM, Tarnopolsky MA, Hogben CD, Ballantyne CS, MacDougall JD. Post exercise hypotension is not mediated by the serotonergic system in borderline hypertensive individuals. J Hum Hypertens 2002; 16: 33-39, doi: 10.1038/sj.jhh.1001290.

9. Brandao Rondon MU, Alves MJ, Braga AM, Teixeira OT, Barretto AC, Krieger EM, et al. Postexercise blood pressure reduction in elderly hypertensive patients. J Am Coll Cardiol 2002; 39: 676-682, doi: 10.1016/S0735-1097(01)01789-2.

10. Lacombe SP, Goodman JM, Spragg CM, Liu S, Thomas SG. Interval and continuous exercise elicit equivalent postexercise hypotension in prehypertensive men, despite differences in regulation. Appl Physiol Nutr Metab 2011; 36: 881-891, doi: 10.1139/h11-113. weight, presence of hypertension, and recovery in the sitting position. The review suggests that more studies are needed to directly address the influence of these factors. In addition, the different combinations of these factors may favor the reduction of CO or PVR, explaining the different results for $\mathrm{PAEH}$ determinants observed in the literature.

\section{Acknowledgments}

This research was supported by FAPESP (\#2011/ 03584-8 and \#2009/18219-3), CNPq (\#305365-2011-8), and CAPES-PROEX.

11. Liu S, Goodman J, Nolan R, Lacombe S, Thomas SG. Blood pressure responses to acute and chronic exercise are related in prehypertension. Med Sci Sports Exerc 2012; 44: 1644-1652, doi: 10.1249/MSS.0b013e31825408fb.

12. Dujic Z, Ivancev V, Valic Z, Bakovic D, Marinovic-Terzic I, Eterovic D, et al. Postexercise hypotension in moderately trained athletes after maximal exercise. Med Sci Sports Exerc 2006; 38: 318-322, doi: 10.1249/01.mss.0000 187460.73235.3b

13. Forjaz CL, Matsudaira $\mathrm{Y}$, Rodrigues FB, Nunes N, Negrao $\mathrm{CE}$. Post-exercise changes in blood pressure, heart rate and rate pressure product at different exercise intensities in normotensive humans. Braz J Med Biol Res 1998; 31: 12471255, doi: 10.1590/S0100-879X1998001000003.

14. Forjaz CL, Santaella DF, Rezende LO, Barretto AC, Negrao CE. [Effect of exercise duration on the magnitude and duration of post-exercise hypotension]. Arq Bras Cardiol 1998; 70: 99-104, doi: 10.1590/S0066-782X199800020 0006.

15. Hamer M, Boutcher SH. Impact of moderate overweight and body composition on postexercise hemodynamic responses in healthy men. J Hum Hypertens 2006; 20: 612-617, doi: 10.1038/sj.jhh.1002035.

16. Jones $\mathrm{H}$, George K, Edwards B, Atkinson G. Is the magnitude of acute post-exercise hypotension mediated by exercise intensity or total work done? Eur J Appl Physiol 2007; 102: 33-40, doi: 10.1007/s00421-007-0562-0.

17. Lockwood JM, Pricher MP, Wilkins BW, Holowatz LA, Halliwill JR. Postexercise hypotension is not explained by a prostaglandin-dependent peripheral vasodilation. J Appl Physiol 2005; 98: 447-453, doi: 10.1152/japplphysiol.00787.2004.

18. Lockwood JM, Wilkins BW, Halliwill JR. H1 receptormediated vasodilatation contributes to postexercise hypotension. J Physiol 2005; 563: 633-642, doi: 10.1113/ jphysiol.2004.080325.

19. Lynn BM, Minson CT, Halliwill JR. Fluid replacement and heat stress during exercise alter post-exercise cardiac haemodynamics in endurance exercise-trained men. J Physiol 2009; 587: 3605-3617, doi: 10.1113/jphysiol.2009.171199.

20. McCord JL, Beasley JM, Halliwill JR. H2-receptor-mediated vasodilation contributes to postexercise hypotension. J Appl Physiol 2006; 100: 67-75, doi: 10.1152/japplphysiol.00959. 2005. 
21. Raine NM, Cable NT, George KP, Campbell IG. The influence of recovery posture on post-exercise hypotension in normotensive men. Med Sci Sports Exerc 2001; 33: 404412, doi: 10.1097/00005768-200103000-00012.

22. Scott JM, Esch BT, Lusina SJ, McKenzie DC, Koehle MS, Sheel AW, et al. Post-exercise hypotension and cardiovascular responses to moderate orthostatic stress in endurance-trained males. Appl Physiol Nutr Metab 2008; 33: 246253, doi: 10.1139/H07-173.

23. Senitko AN, Charkoudian N, Halliwill JR. Influence of endurance exercise training status and gender on postexercise hypotension. J Appl Physiol 2002; 92: 2368-2374, doi: $10.1063 / 1.1497451$

24. Teixeira L, Ritti-Dias RM, Tinucci T, Mion Junior D, Forjaz CL. Post-concurrent exercise hemodynamics and cardiac autonomic modulation. Eur J Appl Physiol 2011; 111: 20692078, doi: 10.1007/s00421-010-1811-1.

25. Harvey PJ, Morris BL, Kubo T, Picton PE, Su WS, Notarius $C F$, et al. Hemodynamic after-effects of acute dynamic exercise in sedentary normotensive postmenopausal women. J Hypertens 2005; 23: 285-292, doi: 10.1097/ 00004872-200502000-00010.

26. Halliwill JR, Taylor JA, Eckberg DL. Impaired sympathetic vascular regulation in humans after acute dynamic exercise. J Physiol 1996; 495 (Part 1): 279-288.

27. Halliwill JR, Taylor JA, Hartwig TD, Eckberg DL. Augmented baroreflex heart rate gain after moderate-intensity, dynamic exercise. Am J Physiol 1996; 270: R420-R426.

28. Forjaz CL, Cardoso CG Jr, Rezk CC, Santaella DF, Tinucci T. Postexercise hypotension and hemodynamics: the role of exercise intensity. J Sports Med Phys Fitness 2004; 44: 54-62.

29. Halliwill JR, Minson CT, Joyner MJ. Effect of systemic nitric oxide synthase inhibition on postexercise hypotension in humans. J Appl Physiol 2000; 89: 1830-1836.

30. Endo MY, Kajimoto C, Yamada M, Miura A, Hayashi N, Koga $S$, et al. Acute effect of oral water intake during exercise on post-exercise hypotension. Eur J Clin Nutr 2012; 66: 1208-1213, doi: 10.1038/ejcn.2012.139.

31. Floras JS, Wesche J. Haemodynamic contributions to postexercise hypotension in young adults with hypertension and rapid resting heart rates. J Hum Hypertens 1992; 6: 265-269.

32. Rueckert PA, Slane PR, Lillis DL, Hanson P. Hemodynamic patterns and duration of post-dynamic exercise hypotension in hypertensive humans. Med Sci Sports Exerc 1996; 28: 24-32, doi: 10.1097/00005768-199601000-00010.

33. Takahashi T, Okada A, Saitoh T, Hayano J, Miyamoto Y. Difference in human cardiovascular response between upright and supine recovery from upright cycle exercise. Eur J Appl Physiol 2000; 81: 233-239, doi: 10.1007/s0042 10050036.

34. Carter R III, Watenpaugh DE, Smith ML. Gender differences in cardiovascular regulation during recovery from exercise. J Appl Physiol 2001; 91: 1902-1907.

35. Beaulieu M, Nadeau A, Lacourciere Y, Cleroux J. Postexercise reduction in blood pressure in hypertensive subjects: effects of angiotensin converting enzyme inhibition. Br J Clin Pharmacol 1993; 36: 331-338, doi: 10.1111/ j.1365-2125.1993.tb00372.x.

36. Piepoli M, Coats AJ, Adamopoulos S, Bernardi L, Feng YH, Conway $\mathrm{J}$, et al. Persistent peripheral vasodilation and sympathetic activity in hypotension after maximal exercise. J Appl Physiol 1993; 75: 1807-1814.

37. Casiglia E, Palatini P, Bongiovi S, Mario L, Colangeli G, Ginocchio G, et al. Haemodynamics of recovery after strenuous exercise in physically trained hypertensive and normotensive subjects. Clin Sci 1994; 86: 27-34.

38. Piepoli M, Isea JE, Pannarale G, Adamopoulos S, Sleight P, Coats AJ. Load dependence of changes in forearm and peripheral vascular resistance after acute leg exercise in man. J Physiol 1994; 478 (Part 2): 357-362.

39. Headley SA, Keenan TG, Manos TM, Phillips K, Lachowetz $T$, Keenan HA, et al. Renin and hemodynamic responses to exercise in borderline hypertensives. Ethn Dis 1998; 8: 312318.

40. Pescatello LS, Miller B, Danias PG, Werner M, Hess M, Baker $\mathrm{C}$, et al. Dynamic exercise normalizes resting blood pressure in mildly hypertensive premenopausal women Am Heart J 1999; 138: 916-921, doi: 10.1016/S0002-8703(99) 70017-7.

41. Figueroa A, Baynard T, Fernhall B, Carhart R, Kanaley JA Impaired postexercise cardiovascular autonomic modulation in middle-aged women with type 2 diabetes. Eur $J$ Cardiovasc Prev Rehabil 2007; 14: 237-243, doi: 10.1097/ HJR.0b013e32801da10d.

42. Lynn BM, McCord JL, Halliwill JR. Effects of the menstrual cycle and sex on postexercise hemodynamics. Am J Physiol Regul Integr Comp Physiol 2007; 292: R1260-R1270, doi: 10.1152/ajpregu.00589.2006.

43. New KJ, Reilly ME, Templeton K, Ellis G, James PE, Mceneny $\mathrm{J}$, et al. Free radical-mediated lipid peroxidation and systemic nitric oxide bioavailability: implications for postexercise hemodynamics. Am J Hypertens 2013; 26: 126-134, doi: 10.1093/ajh/hps025.

44. Isea JE, Piepoli M, Adamopoulos S, Pannarale G, Sleight P, Coats AJ. Time course of haemodynamic changes after maximal exercise. Eur J Clin Invest 1994; 24: 824-829, doi: 10.1111/j.1365-2362.1994.tb02026.x.

45. Izdebska E, Cybulska I, Sawicki M, Izdebski J, Trzebski A. Postexercise decrease in arterial blood pressure, total peripheral resistance and in circulatory responses to brief hyperoxia in subjects with mild essential hypertension. $J$ Hum Hypertens 1998; 12: 855-860, doi: 10.1038/sj.jhh.1000716.

46. Birch K, Cable N, George K. Combined oral contraceptives do not influence post-exercise hypotension in women. Exp Physiol 2002; 87: 623-632, doi: 10.1113/eph8702400.

47. Journeay WS, Reardon FD, Martin CR, Kenny GP. Control of cutaneous vascular conductance and sweating during recovery from dynamic exercise in humans. J Appl Physiol 2004; 96: 2207-2212, doi: 10.1152/japplphysiol.01201.2003.

48. Journeay WS, Reardon FD, Mclnnis NH, Kenny GP. Nonthermoregulatory control of cutaneous vascular conductance and sweating during recovery from dynamic exercise in women. J Appl Physiol 2005; 99: 1816-1821, doi: 10.1152/japplphysiol.00497.2005.

49. Esformes JI, Norman F, Sigley J, Birch KM. The influence of menstrual cycle phase upon postexercise hypotension. Med Sci Sports Exerc 2006; 38: 484-491, doi: 10.1249/ 01.mss.0000193559.98095.ea.

50. McCord JL, Halliwill JR. $\mathrm{H} 1$ and $\mathrm{H} 2$ receptors mediate postexercise hyperemia in sedentary and endurance exercise-trained men and women. J Appl Physiol 2006; 101: 
1693-1701, doi: 10.1152/japplphysiol.00441.2006.

51. Journeay WS, Jay O, Mclnnis NH, Leclair E, Kenny GP. Postexercise heat loss and hemodynamic responses during head-down tilt are similar between genders. Med Sci Sports Exerc 2007; 39: 1308-1314, doi: 10.1249/mss.0b013e3180 $6865 \mathrm{e} 0$.

52. Jones H, Pritchard C, George K, Edwards B, Atkinson G. The acute post-exercise response of blood pressure varies with time of day. Eur J Appl Physiol 2008; 104: 481-489, doi: 10.1007/s00421-008-0797-4.

53. Jones H, George K, Edwards B, Atkinson G. Effects of time of day on post-exercise blood pressure: circadian or sleeprelated influences? Chronobiol Int 2008; 25: 987-998, doi: $10.1080 / 07420520802548044$.

54. Gallahue DL, Ozmun JC, Goodway JD. Understanding motor development: infants, children, adolescents, adults. 7th edn. New York: The McGraw-Hill Companies; 2012.

55. Chobanian AV, Bakris GL, Black HR, Cushman WC, Green LA, Izzo JL Jr, et al. Seventh report of the Joint National Committee on Prevention, Detection, Evaluation, and Treatment of High Blood Pressure. Hypertension 2003; 42: 1206-1252, doi: 10.1161/01.HYP.0000107251.49515.c2.

56. Rossow L, Yan H, Fahs CA, Ranadive SM, Agiovlasitis S, Wilund KR, et al. Postexercise hypotension in an endurance-trained population of men and women following highintensity interval and steady-state cycling. Am J Hypertens 2010; 23: 358-367, doi: 10.1038/ajh.2009.269.

57. Lakatta EG, Levy D. Arterial and cardiac aging: major shareholders in cardiovascular disease enterprises: Part II: the aging heart in health: links to heart disease. Circulation 2003; 107: 346-354, doi: 10.1161/01.CIR.0000048893.62841.F7.

58. Evans JM, Ziegler MG, Patwardhan AR, Ott JB, Kim CS, Leonelli FM, et al. Gender differences in autonomic cardiovascular regulation: spectral, hormonal, and hemodynamic indexes. J Appl Physiol 2001; 91: 2611-2618.

59. Krabbendam I, Maas ML, Thijssen DH, Oyen WJ, Lotgering FK, Hopman MT, et al. Exercise-induced changes in venous vascular function in nonpregnant formerly preeclamptic women. Reprod Sci 2009; 16: 414-420, doi: 10.1177/ 1933719109332091.

60. Avogaro A, De Kreutzenberg SV. Mechanisms of endothelial dysfunction in obesity. Clin Chim Acta 2005; 360: 9-26, doi: 10.1016/j.cccn.2005.04.020.

61. Kopelman PG. Obesity as a medical problem. Nature 2000; 404: 635-643.
62. MacDonald JR, MacDougall JD, Hogben CD. The effects of exercise duration on post-exercise hypotension. J Hum Hypertens 2000; 14: 125-129, doi: 10.1038/sj.jhh.1000953.

63. Pescatello LS, Franklin BA, Fagard R, Farquhar WB, Kelley GA, Ray CA. American College of Sports Medicine position stand. Exercise and hypertension. Med Sci Sports Exerc 2004; 36: 533-553, doi: 10.1249/01.MSS.0000115224. 88514.3A.

64. Santana HA, Moreira SR, Asano RY, Sales MM, Cordova C, Campbell CS, et al. Exercise intensity modulates nitric oxide and blood pressure responses in hypertensive older women. Aging Clin Exp Res 2013; 25: 43-48, doi: 10.1007/s40520-013-0017-x.

65. Voogel AJ, Koopman MG, Hart AA, van Montfrans GA, Arisz L. Circadian rhythms in systemic hemodynamics and renal function in healthy subjects and patients with nephrotic syndrome. Kidney Int 2001; 59: 1873-1880, doi: 10.1046/ j.1523-1755.2001.0590051873.x.

66. Hermida RC, Ayala DE, Portaluppi F. Circadian variation of blood pressure: the basis for the chronotherapy of hypertension. Adv Drug Deliv Rev 2007; 59: 904-922, doi: 10.1016/j.addr.2006.08.003.

67. Gotshall RW, Aten LA, Yumikura S. Difference in the cardiovascular response to prolonged sitting in men and women. Can J Appl Physiol 1994; 19: 215-225, doi: 10.1139/h94-016.

68. Mark AL, Mancia G. Cardiopulmonary baroreflex in humans. In: Rowell LB, Shepherd JT (Editors), Handbook of physiology. New york: Oxford; 1996. p 795-813.

69. Halliwill JR, Buck TM, Lacewell AN, Romero SA Postexercise hypotension and sustained postexercise vasodilatation: what happens after we exercise? Exp Physiol 2013; 98: 7-18, doi: 10.1113/expphysiol.2011.058065.

70. Heffernan KS, Collier SR, Kelly EE, Jae SY, Fernhall B. Arterial stiffness and baroreflex sensitivity following bouts of aerobic and resistance exercise. Int J Sports Med 2007; 28 : 197-203, doi: 10.1055/s-2006-924290.

71. Grassi G. Assessment of sympathetic cardiovascular drive in human hypertension: achievements and perspectives. Hypertension 2009; 54: 690-697, doi: 10.1161/HYPERTE NSIONAHA.108.119883.

72. Sevre K, Lefrandt JD, Nordby G, Os I, Mulder M, Gans RO, et al. Autonomic function in hypertensive and normotensive subjects: the importance of gender. Hypertension 2001; 37 : 1351-1356, doi: 10.1161/01.HYP.37.6.1351. 